\title{
Retirement and Aging Parents in the Swedish Population
}

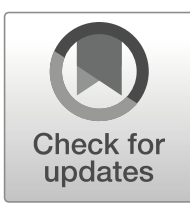

\author{
Linda Kridahl $^{1} \cdot$ Merril Silverstein $^{2}$
}

Received: 27 October 2017 / Accepted: 5 March 2019 / Published online: 2 April 2019

(C) The Author(s) 2019

\begin{abstract}
The workforce is aging in most developed countries. Simultaneously, the parents of workers nearing retirement age are more likely to still be alive and in need of care. This study investigated the association between retirement transition and parental vital status in Sweden. The data were derived from Swedish population registers of women and men born between 1940 and 1945. A discrete-time survival analysis using complementary log-log functions was employed. The outcome was individuals' retirement transition, and the main dependent variable was parental vital status, e.g., whether the mother, father or both parents were alive in the year that the individual retired. We also controlled for whether either one or both parents recently died prior to the retirement transition. This study's findings indicate that the parental vital status has an independent, but relatively small, influence on individuals' retirement transition and that the association is somewhat stronger and more consistent among women than men, particularly women with only a living mother or father (approximately 8 and 6\% higher risk of retirement, respectively). Additionally, women had a higher risk of retirement during the immediate period after parental death, especially when the father was widowed ( $9 \%$ higher risk). In contrast, men had a $9 \%$ higher risk of retiring when either the mother or father had been widowed for some years. Moreover, siblings seem to moderate the effect of retirement, and the pattern was most noticeable among women. Overall, the risk of retirement was greater among individuals without siblings with both living parents or only a living mother or father. These findings indicate that individuals with parents who are vulnerable due to widowhood are able to work longer if they have larger families, which is consistent with the caregiving explanation. This relationship was more evident among women, providing support for the conclusion that care provision for parents may motivate labor force disengagement in the form of retirement.
\end{abstract}

Keywords Retirement $\cdot$ Parental vital status $\cdot$ Eldercare $\cdot$ Nordic country

Linda Kridahl

linda.kridahl@sociology.su.se

Extended author information available on the last page of the article 


\section{Introduction}

The decision to retire from paid work is a complex and dynamic process in which past, current, and future life conditions play a role (Feldman and Beehr 2011). Retirement is influenced by various constraints and inducements, such as health status (Barnes-Farell 2003; Kim and Feldman 2000), economic well-being (Hayward et al. 1998), the value placed on leisure (Higgs et al. 2003; Kridahl 2015), and family considerations (Dentinger and Clarkberg 2002). Increasingly, retirement has been decoupled from age (O'Rand and Henretta 1999), rendering retirement a flexible arrangement that is sensitive to various contingencies. In most Western countries, the labor force is aging due to changing population structures. Pension policy reforms are designed to increase the labor supply, and Sweden is no exception. Furthermore, due to gains in longevity, workers are highly likely to approach the traditional retirement age with one or two surviving parents, raising questions regarding how the presence or absence of aging parents shapes retirement transition.

In this investigation, we focused on the association between retirement transition and having living older parents in Sweden. Using data from population registries, we examined how cohorts approaching retirement age respond to having both living parents, one living parent, or two deceased parents. We propose that having two living parents may enhance the risk of retirement due to obligations related to caring for elderly parents. Furthermore, the death of one parent could enhance the risk of retirement even more because of the additional attention and care the sole parent may require. This research also contributes to a broader understanding of family demands for parent care by considering the availability of siblings as a moderator of the competition between work and parental needs. Previous studies investigating the effect of parental caregiving on retirement and labor force reduction have mainly used small samples and/or only studied women in elderly cohorts (Hatch and Thompson 1992; Himes 1994; Svensson et al. 2015). The novelty of our study is that we investigate both men and women from cohorts retiring in contemporary Sweden using large-scale high quality longitudinal administrative data, which allow us to follow in parallel parental deaths and retirement transitions over a very long time.

This study is informed by the life course perspective, particularly the principle of linked lives, which considers human actions to be influenced by the life circumstances of close relatives (Elder et al. 2003). From this perspective, retirement is contingent on alternative engagements and obligations related mostly to family ties. Moreover, men and women traditionally have different life course trajectories; men primarily engage in paid labor, while women engage in both paid labor and care work. Thus, retirement transition among women may be more sensitive to family demands than retirement transition among men.

\section{Family Ties, Work, and Retirement}

Numerous studies have identified the importance of family circumstances in retirement decision making, and most investigations have focused on the presence and characteristics of spouses, children, and grandchildren (Svensson et al. 2015; Szinovacz and Deviney 2000; Szinovacz et al. 2001). When aging parents need help, adult children, 
mainly daughters, frequently become their caregivers (Eggebeen 1992; Szebehely and Ulmanen 2009). These caregiving responsibilities often compete with work responsibilities and may generate additional stress (Soldo and Myllyluoma 1983). As women are generally less attached to the labor market and assume responsibility for most family obligations, they also tend to reduce their labor force participation due to their responsibilities of caring for kin. Hence, caring for older parents has been shown to reduce labor force participation among women, especially when pension benefits are available (Doty 1995; Hatch and Thompson 1992; Himes 1994; Moen et al. 1994; Stueve and O'Donnell 1989); vice versa, employment has been shown to constrain the levels of caring for parents (Doty 1995; Stueve and O’Donnell 1989). However, Bolin et al. (Bolin et al. 2008) conducted a cross-national study and found that both women and men reduced the number of working hours to care for elderly parents, particularly in Northern Europe, including Sweden. To the best of our knowledge, only one study presented results related to the influence of elderly parents on their adult children's retirement transition. Svensson et al. (2015) used Swedish population register data to study how retirement transition was entwined with different types of family life courses among women born in 1935 during the 1990-2006 period. Among their findings, these authors reported a significant (but weak) association between having a surviving parent and an earlier retirement. The positive association between the parents' vital status and retirement transition in their restricted study population involving women from one cohort pander for a large-scale investigation, such as ours, in which women and men from several younger cohorts are studied.

Moreover, whether the parent lives with a partner may play a role in their need for attention and care. Studies have shown that parents who are widowed are most vulnerable and more likely to suffer from poor health (Silverstein and Bengtson 1994; Umberson et al. 1992). Widowed fathers may be especially vulnerable because they lack the skills necessary for household management (Umberson et al. 1992). The relationship between older parents and adult children has been shown to strengthen after the death of the other parent (Eggebeen 1992; Roan and Raley 1996). In addition, the death of a parent has negative consequences on the adult children's health and wellbeing, particularly shortly after the death (Leopold and Lechner 2015; Umberson 2003). Therefore, presumably, the risk of retirement may differ depending on whether the parent is widowed, the gender of the parent, and the time since the parental death. In addition, having siblings may ease the burden of filial responsibilities (Campbell and Martin-Matthews 2003; Stoller et al. 1992; Wolf et al. 1997).

Research has also shown that people with dependent children are more likely to retire later mainly due to having financial obligations for minor children (Raymo and Sweeney 2006). Moreover, comparative studies have found that grandparents in Sweden commonly provide grandchild care (Albertini et al. 2007; Hank and Buber 2009). Several studies investigating the importance of grandparenthood in retirement transition have found that grandparenthood increases the likelihood of early retirement (Hochman and Lewin-Epstein 2013; Kridahl 2015). Moreover, depending on gender, caregiving for a spouse may either postpone or accelerate retirement. For instance, studies have found that husbands of disabled wives continue to participate in the labor market, while wives of disabled husbands retire earlier (Dentinger and Clarkberg 2002; Hayward et al. 1998; Szinovacz and Deviney 2000). In addition to family factors, the other prime determinants of the decision to retire include the age of pension eligibility 
and pension entitlements, socioeconomic status and health. Individuals occupying professional positions tend to have less physically demanding and more rewarding jobs, which may encourage later retirement (Blekesaune and Solem 2005). However, greater economic resources and more generous pension benefits encourage earlier retirement (Duval 2003; Gruber and Wise 1999; Radl 2013). Additionally, many studies have documented a health gradient in retirement such that less healthy workers are more likely to retire than healthier workers (Karpansalo et al. 2005; McGarry 2004; Sell 2009). In particular, individuals who receive sickness benefits are more likely to retire earlier (Johansson et al. 2014). Previous work has also indicated a greater risk of earlier retirement among those living in the more rural areas of Sweden (Hartig and Fransson 2006; Statistics Sweden 2011).

Retirement is a complex life transition, and considering a wide range of personal and family characteristics, such as the parental vital status, which is the focus of this study, is essential for studying retirement. For instance, the presence of children and indicators of health status have been shown to be key determinates of retirement decisions regarding either early retirement or the postponement of retirement. However, the same determinants may be central to the opportunity and intention to engage in filial care. For instance, having many children or a poor health status may hinder the care of elderly parents. Hence, by including some of these determinates in our models, we control for underlying effects that may impact retirement transition and, thus, produce more robust and clear results regarding the association between retirement transition and the parental vital status.

\section{Sweden as a Strategic Site for Research Investigating Retirement and Family Ties}

The Swedish context provides several distinct advantages for examining the relationship between retirement and the vital status of parents. These advantages are related to Sweden's rate of population aging, long-term care policy, pension reform, and integrated data infrastructure.

First, Sweden has a growing older population with relatively high life expectancies and decreased mortality among older adults, which is projected to continue not only among those aged 65 to 79 years but also among those aged 80 years or older (Statistics Sweden 2018). This development implies that retirement decisions will increasingly occur while one or both parents are alive but experiencing some degree of frailty before death.

Second, the publicly financed eldercare system in Sweden aims to provide older individuals the opportunity to live independently outside of long-term care facilities for as long as possible even when in need of extensive care (Social Service Act 1980:620, Social Service Act 2001:453). Due to this political situation, families are more likely to be involved with the care of their older family members in a way that complements formal in-home eldercare services. Despite the strong social care policies that serve the needs of older people, adult children in Sweden tend to have frequent contact with their elderly parents (Daatland and Lowenstein 2005; Ogg and Renaut 2006). In addition, informal care, particularly care provided by middle-aged daughters and wives, has increased in Sweden (Szebehely 1999; Szebehely and Ulmanen 2009). Although the extensive public eldercare in Sweden has strengthened women's participation in the 
paid labor force (Lilly et al. 2007; Sundström et al. 2002; Ulmanen 2013), access to informal care has increased partially due to the increasing availability of kin (Sundström 2009) and the decline in the use of formal care due to eligibility restrictions (Sundström et al. 2002; Ulmanen and Szebehely 2015). Scholars argue that dependence on family support networks could become more important in the coming decades (Sundström et al. 2006; Marta Szebehely and Trygdegård 2012).

Third, due to Sweden's high rates of labor force participation among both men and women (OECD 2019; Statistics Sweden 2014) and gender-neutral public pension system (Sundén 2006), it is possible to study both men's and women's retirement motivations under equal pension conditions. However, as in most countries, men and women do not engage equally in the labor market. Women tend to have longer work disruptions and shorter working hours and work more part-time, suggesting that women, in general, have lower incomes and pensions than men (Statistics Sweden 2014). Given their stronger filial norms and their weaker ties to the labor market, we argue that women are more likely than men to retire to meet their family needs.

Fourth, Swedish workers are increasingly delaying retirement, although at a slow pace. This change is partially the result of the new pension system fully implemented in 2003, which abolished the mandatory pension age and offers employees the flexibility to decide when to retire beginning at the age of 61 without any upper age limit. There are disadvantages to working past the age of 67 as these workers are not covered by unemployment insurance, sickness insurance or the Employment Protection Act. Nevertheless, the system encourages workers to postpone their labor force exit as additional time in the paid labor market generates higher pension benefits (Palme and Svensson 2004; Sundén 2006). Individuals who retire can continue to work while receiving part-time pension benefits. There are also several options to retire early through occupational pension schemes, which cover approximately $95 \%$ of the labor force (Palme and Svensson 1999).

The new pension system was introduced gradually, and as a result, cohorts born between 1940 and 1945 receive pension benefits from both the old and new systems. In the new system, life-long contributions matter, and one's annual benefit level is automatically adjusted to the increasing life expectancy, suggesting that younger cohorts need to postpone retirement to receive replacement rates equal to those of the older cohorts. However, this system does not strongly affect cohorts born between 1940 and 1945 as the retirement age required to neutralize the effect of the increased life expectancy is calculated to be 65-65.5 years. Younger cohorts could be more affected by the new system than cohorts born in the 1940s, particularly due to the lower income replacement rates (Flood 2007; Sjögren Lindquist and Wadensjö 2009; Sundén 2006; Swedish Social Insurance Agency 2005). As a result of the changes to the pension policy, the average effective retirement age has increased during the 2003-2012 period from 64 to 66.1 for men and from 61.8 to 64.3 for women (OECD 2017), and the current variations in the age of retirement are larger than those in earlier pension systems.

Finally, Sweden offers significant advantages for studies investigating life course transitions, demographic behaviors, and kin-supply due to the data infrastructure of linked registries. Sweden has unique high-quality longitudinal population data related to inter- and intragenerational ties, labor force earnings, and old-age pension benefits; thus, evaluating the contribution of multiple kin relationships, health and wealth to retirement transition is possible. 


\section{Study Hypotheses}

This study investigated whether having living older parents is associated with retirement decisions within the Swedish-born population of women and men in the 1940-1945 birth cohort. Under the assumption that many retirees have retired to care for vulnerable elderly parents, we hypothesize that individuals with both living parents have a higher propensity to retire than individuals with two deceased parents (H1). However, previous research has emphasized that the characteristics of an older generation have consequences on the following generation, such as intergenerational transfers of health status, human capital, and income level, which may affect the younger generation's early life and produce latent effects during adulthood (Coneus and Spiess 2012; Elstad 2005). Therefore, it is plausible that individuals whose parents died at younger ages might have a higher propensity to retire. For example, individuals with deceased parents may have poor health or a low socioeconomic status, which are factors strongly related to earlier withdrawal from the labor market. This potential pathway should not be ignored, although we acknowledge the first explanation of filial caregiving in this study. Particularly, we assume that the risk is higher among individuals with widowed $^{1}$ parents; hence, we hypothesize the following: individuals who have one living parent have a higher propensity to retire than those with two living parents $(\mathrm{H} 2)$. As men and women engage differently in family and work over their life course, we also expect that a gender difference exists and hypothesize that women with one living parent have a higher propensity to retire than men with one living parent (H3a). In addition, as daughters care for their elderly parents more often than sons and elderly men are more vulnerable than elderly women, we hypothesize that if H3a is true, women with a widowed father have a higher propensity to retire than men with a widowed father ( $\mathrm{H} 3 \mathrm{~b})$. We also assume that the immediate period after the death of one or both parents is more intense and stressful and, therefore, might have a stronger influence on the propensity to retire than after the immediate period has passed. Hence, we hypothesize that during the immediate period after the death of one parent, the propensity to retire is greater than that if the parent had died some years earlier (H4a). As elderly men are often more vulnerable than elderly women, we hypothesize that if $\mathrm{H} 4 \mathrm{a}$ is true, the propensity to retire is greater when fathers are widowed (H4b). Additionally, as women care for their elderly parents more often than men, we hypothesize that if $\mathrm{H} 4 \mathrm{a}$ is true, the propensity to retire immediately after the death of a parent is greater among women than men $(\mathrm{H} 4 \mathrm{c})$. We also assume that siblings might moderate the strength of the relationship between the parental vital status and propensity for retirement. Hence, the study's final two hypotheses are as follows: the absence of siblings strengthens the relationship between parental vital status and risk of retirement (H5a), particularly among women as women assume the caregiver role for elderly parents more frequently than men (H5b). In summary, the hypotheses are as follows:

\footnotetext{
${ }^{1}$ As we do not have information regarding the parents' marital status, we can only speculate whether the parents were married and, therefore, became widowed after the other parent's death.
} 
Hypothesis 1: Individuals with both living parents have a higher propensity to retire than individuals with two deceased parents.

Hypothesis 2: Individuals who have one living parent have a higher propensity to retire than those with two living parents.

Hypothesis 3a: Women with one living parent have a higher propensity to retire than men with one living parent.

Hypothesis 3b: If $\mathrm{H} 3 \mathrm{a}$ is true, women with a widowed father have a higher propensity to retire than men with a widowed father.

Hypothesis 4a: During the immediate period after the death of one parent, the propensity to retire is greater than that if the parent had died some years earlier.

Hypothesis 4b: If $\mathrm{H} 4 \mathrm{a}$ is true, the propensity to retire is greater when fathers are widowed.

Hypothesis 4c: If H4a is true, the propensity to retire immediately after the death of a parent is greater among women than men.

Hypothesis 5a: The absence of siblings strengthens the relationship between parental vital status and risk of retirement.

Hypothesis 5b: If H5a is true, this relationship is stronger among women than men.

\section{Data and Method}

\section{Study Population}

Our analysis uses information obtained from the following Swedish national population registers: the Multi-Generation Register, the Sick Insurance and Labor Market Studies Database, and Annual Total Population Registers. Each individual was identified by a unique identification number, allowing each individual to be linked to various registers and several generations. The population in this study consisted of more than 400,000 individuals (49\% women) born in Sweden between 1940 and 1945 observed during the 2000-2012 period. We obtained annual records covering this period, and the individuals were observed from the age of 60 until retirement, the age of 70, death, migration, or the end of the study period (depending what comes first). The study population was chosen to provide all cohorts a possibility to reach the age of 67 , suggesting that we captured both early and late retirement (although not related to the statuary retirement age because Sweden does not have such an age). We observed retirements beginning in 2000 to include individuals who retired under the new pension system introduced in 1999-2000.

Several exclusion criteria were applied. First, immigrants were excluded as most immigrants born during the relevant period did not have older parents living in Sweden. Second, individuals who did not have identification numbers for one or both parents were excluded as it was not possible to link their parents to other registers and family members (such as siblings) without an identification number. In total, 64,661 individuals were excluded because of missing identification numbers for the father, 20,802 individuals had missing information regarding the mother, and 20,582 individuals had missing identification numbers for both parents. We also excluded adopted individuals because the uncertainty of the filial relationship is greater among adoptive children as we do not know the exact date of adoption, particularly in the older generations as the 
register data are less reliable in the oldest-old cohorts. We also excluded those who did not have any earnings information during the observed period. In total, $18 \%$ of those in the birth cohort of 1940-1945 who were born in Sweden were excluded from the analysis.

\section{Analytic Approach}

Our analytic approach employed a discrete-time survival analysis using complementary $\log$-log functions with retirement transition as the outcome event. This method is suitable for analyses of longitudinal data organized into discrete temporal intervals, such as calendar years (Allison 2010). In our application, the retirement events occurred somewhere within a calendar year over a period of 13 years. Most individuals were observed for many years. For instance, a person observed beginning at the age of 60 until retirement at the age of 64 contributes 4 person-years to the analysis until he/she is censored. Another individual observed beginning at the age of 60 who never retires during the study interval contributes 10 person-years until he/she is censored after the age of 70. Moreover, the estimated models provided hazard ratios indicative of the risk of retirement throughout the study, which are calculated by the parental vital status controlling for several individual characteristics (presented in the following sections). For instance, the hazard ratios represent the risk of retirement among individuals who have a living mother compared with that among individuals who have both living parents during any time during the study period, which we limited to the age range of 60 to 70 years during the 2000 to 2012 period. Hence, we do not interpret the results or draw conclusions related to any form of "early" or "late" retirement or any other "normative retirement age".

\section{Dependent Variable}

The outcome variable in our analysis was the transition to retirement, which was a timevarying event. To define individuals as retired, we used annual records from the Swedish National Tax Agency (which receives earnings reports from employers), the National Pension Agency and the Swedish Social Insurance Agency. More specifically, we defined the transition to retirement as the first year an individual received annual pension benefits that equaled or exceeded $49 \%$ of the total yearly earnings from annual employment earnings, annual pension benefits, and annual unemployment benefits. This definition of retirement transition has been applied to Swedish register data in other studies and has been shown to have desirable properties compared with several alternative methods (e.g., Kridahl 2015; Kridahl and Kolk 2018; Statistics Sweden 2011).

In our definition, annual pension benefits included all possible pension benefits (earnings-related occupation pension, supplement pension, flat-rate pension, private pension, guarantee pension, premium pension, part-time pension, early pension and disability pension). ${ }^{2}$ The annual employment earnings included employment income, income from self-employment and disability benefits. Using our definition of retirement, the mean age of retirement among the observed individuals during the study

\footnotetext{
$\overline{{ }^{2} \text { For a more detailed presentation }}$ of the Swedish pension system, see Sundén (2006).
} 
period of 2000-2012 is 64.4 for men and 64.2 for women. Table 1 shows the distribution of age of retirement using this definition. In this table, we present the distribution by age, but in the survival analyses, we apply age categories. The distribution is very similar between women and men. As a part of our analytical strategy, we excluded individuals who retired before the age of 60; hence, there is a shift to the right, e.g., retirement occurs at somewhat higher ages (but before the age of 70, which is our upper bound), particularly among women who more often retire before the age of $60 .^{3}$ Most of the population in this study retired at the ages of 65-66 years. Overall, $94 \%$ of all men and $97 \%$ of all women born between 1940 and 1945 had retired by the age of 71 years, died or migrated (which are the time points of censorship).

\section{Independent Variables}

As the focus of this study was whether individuals had living elderly parents during their retirement transition, all individuals in the birth cohort of interest (labeled "index persons") were linked to two parents to ascertain their vital status each year, i.e., variable labeled Parental vital status. The administrative registers of the individuals' vital information provide annual records of parental death; thus, the variable is timevarying. The variable was considered using the following categories: 1) both parents alive, 2) mother alive and father deceased, 3) mother deceased and father alive, and 4) both parents deceased. As a proxy for the immediate period after parental death, we controlled for whether the mother, father or both parents recently died (variable labeled Recent death of parent or parents). "Recent death" refers to parental death during the same year as retirement or the year preceding retirement, and the motivation for using this definition is three-fold. First, adult children may more extensively care for elderly parents close to the time of the other parent's death. Second, the parent's final period before death and death itself may negatively influence the adult child. Third, in cases where the death of a parent results in one parent being widowed, the adult child may need to care for the widowed parent, particularly during the period of adaptation to the new life situation. This variable is time-varying and categorized as follows: 1) no parent died during the same year as retirement or the year preceding retirement, 2) the mother died during the same year as retirement or the year preceding retirement, 3) the father died during the same year as retirement or the year preceding retirement, and 4) both parents died during the same year as retirement or the year preceding retirement.

In addition, we controlled for competing reasons for retirement related to the availability of other family members by linking the index persons to registry information about their children, grandchildren, and siblings. We included the following variables in our analysis: number of children, geographic distance to children, age at first birth, the presence of grandchildren, number of siblings, and the presence of a spouse. All variables are time-varying; thus, when an event occurs, such as the birth of a new grandchild or death of a sibling, the variables change accordingly.

The models also included the following additional control variables, many of which are time-varying, that have been shown to influence retirement transition in previous research: gender, age, calendar year, the highest level of achieved education, civil

\footnotetext{
${ }^{3}$ Without the lower age restriction (i.e., exclusion of individuals aged below 60 years), the mean age of retirement is 61.8 for women and 62.2 for men.
} 
Table 1 Age of retirement among individuals born between 1940 and 1945 who retired during the study period of 2000-2012

\begin{tabular}{llll}
\hline Age of retirement among those who retired & & Men \% & Women \% \\
\hline Age of retirement & 60 & 6 & 7 \\
& 61 & 8 & 7 \\
& 62 & 8 & 8 \\
& 63 & 8 & 9 \\
& 64 & 10 & 11 \\
& 65 & 26 & 28 \\
& 66 & 25 & 22 \\
& 67 & 6 & 2 \\
& 68 & $>1$ & $>1$ \\
Total \% & 69 & $>1$ & $>1$ \\
Number of retired individuals & 70 & 100 & 100 \\
Number of individuals & & 194,877 & 188,738 \\
\hline
\end{tabular}

status, place of residence, income, and receipt of sick-leave benefits. The categorization of education followed the international education classifications ISCED 97. This variable included the following categories: low education, including no education; primary education and lower secondary level education (ISCED 0-2); moderate education, secondary education and postsecondary/nontertiary education (ISCED 3-4); and high education consisting of tertiary education (ISCED 5-6). Civil status was categorized into married/registered partner, divorced, widow/widower, and unmarried. Here, individuals defined as unmarried may in reality be involved in a living-apart relationship or cohabiting, but these forms of unions are not registered in Swedish registers. Income was measured by using disposable personal income, which was standardized based on the consumer price index in 1998, and includes employment income, self-employment income, social insurance benefits, house allowance, pension benefits, and capital profits. As retirement is more likely to be affected by past income than income earned during the same year as retirement, income is lagged by 1 year. The place of residence was defined by standardized homogeneous regions generated for distinct geographical areas in Sweden and categorized as metropolitan cities and suburbs, larger-sized cities, medium-sized communities, small-sized communities, and countryside (Statistics Sweden 2003).

To represent the health status, we relied on a measure of the total number of days with sick-leave benefits per year as reported to the Social Insurance Agency. Sick-leave has been shown to be a valid proxy for self-reported health (Drobnič 2002; Josephson et al. 2008). We lagged this variable by 1 year to allow sick days to be assessed over a complete calendar year of employment, which could vary from 1 to 365 days. This variable was categorized as follows: no sick-leave, 1-14 days/year, 15-30 days/year, 31-60 days/year, 61-90 days/year, and 91-365(366) days/year. The descriptive statistics of all variables are presented in Table 2. 
Table 2 Characteristics of cohorts born between 1940 and 1945 at the age of 60 years by gender

\begin{tabular}{|c|c|c|c|}
\hline Variable & & Men $\%$ & Women $\%$ \\
\hline \multirow[t]{4}{*}{ Parental vital status } & Both mother and father alive & 2 & 2 \\
\hline & Mother alive, father deceased & 18 & 19 \\
\hline & Mother deceased, father alive & 5 & 5 \\
\hline & Both mother and father deceased & 74 & 73 \\
\hline \multirow[t]{5}{*}{ Year of birth } & 1940 & 12 & 13 \\
\hline & 1942 & 16 & 16 \\
\hline & 1943 & 18 & 18 \\
\hline & 1944 & 20 & 19 \\
\hline & 1945 & 20 & 20 \\
\hline \multirow[t]{2}{*}{ Father's year of birth } & Before 1910 & 44 & 44 \\
\hline & $1910-1929$ & 56 & 56 \\
\hline \multirow[t]{2}{*}{ Mother's year of birth } & Before 1910 & 26 & 26 \\
\hline & $1910-1930$ & 74 & 74 \\
\hline \multirow[t]{7}{*}{ Age at first birth } & Below 20 & 2 & 11 \\
\hline & $20-24$ & 27 & 38 \\
\hline & $25-29$ & 35 & 29 \\
\hline & $30-34$ & 14 & 8 \\
\hline & $35-39$ & 4 & 2 \\
\hline & 40 or older & 2 & 1 \\
\hline & No children & 16 & 11 \\
\hline \multirow[t]{5}{*}{ Number of children } & 1-2 children & 57 & 61 \\
\hline & 3 children & 19 & 21 \\
\hline & 4 children & 6 & 5 \\
\hline & 5 or more children & 2 & 2 \\
\hline & No children & 16 & 11 \\
\hline \multirow[t]{9}{*}{ Geographical distance to children } & Majority live closer than $21 \mathrm{~km}$ & 42 & 45 \\
\hline & Majority live $21-100 \mathrm{~km}$ away & 8 & 8 \\
\hline & Majority live $101+\mathrm{km}$ away & 11 & 11 \\
\hline & Some live $<21 \mathrm{~km}$, some live $21-100 \mathrm{~km}$ & 8 & 9 \\
\hline & Some live $<21 \mathrm{~km}$, some live $101+\mathrm{km}$ & 8 & 8 \\
\hline & Some live $21-100 \mathrm{~km}$, some live $101+\mathrm{km}$ & 3 & 3 \\
\hline & At all distances & 2 & 2 \\
\hline & Lack information regarding all or most children & 1 & 2 \\
\hline & No children & 16 & 11 \\
\hline \multirow[t]{2}{*}{ Grandchildren } & No grandchildren & 64 & 62 \\
\hline & At least one grandchild & 36 & 38 \\
\hline \multirow[t]{4}{*}{ Civil status } & Married & 69 & 67 \\
\hline & Divorced & 17 & 19 \\
\hline & Widow/Widower & 2 & 6 \\
\hline & Never married & 13 & 8 \\
\hline \multirow[t]{2}{*}{ Highest education achieved } & Tertiary & 25 & 30 \\
\hline & Secondary & 41 & 43 \\
\hline
\end{tabular}


Table 2 (continued)

\begin{tabular}{llll}
\hline Variable & & Men \% & Women \% \\
\hline \multirow{3}{*}{ Place of residence } & Primary & 34 & 27 \\
& Metropolitan cities/suburbs & 31 & 33 \\
Sick-leave in days & All other regions & 69 & 67 \\
& No sick-leave & 83 & 75 \\
& $1-14$ days & 3 & 4 \\
& $15-30$ days & 2 & 3 \\
Number of siblings & $31-60$ days & 2 & 3 \\
& $61-90$ days & 1 & 2 \\
& $91-365$ (366) days & 9 & 13 \\
& No siblings & 17 & 17 \\
& 1 sibling & 33 & 33 \\
& 2 siblings & 24 & 24 \\
& 3 or more siblings & 26 & 26 \\
& & 206,303 & 195,293 \\
\hline
\end{tabular}

\section{Results}

\section{Descriptive Findings}

Figure 1 displays the results of a decrement schedule of parental vital status in the studied cohort aged 60-70 years with the men and women pooled. At the age of 60 years, 25\% (approximately 120,000 individuals) of the index individuals had at least one living parent, including $2 \%$ with both living parents, $18 \%$ with only a living mother, and $5 \%$ with only a living father. Even at ages when retirement typically occurs in Sweden, at the approximate age of 64-65 years (Table 1), there were relatively large proportions of individuals with at least one living parent (approximately $10-15 \%$ ). As the age of the index person increased, parental survival was expected to decrease, which is also the case for retirement age (Table 1).

To provide an overview of the studied cohorts, we present the characteristics of the individuals at the age of 60 years in Table 2, but the forthcoming survival analyses include time-varying variables. We choose the age of 60 because that is the first age of observation. The descriptive findings show that most of the population had children, and most individuals had either one or two children (57\% and $61 \%$ among the men and women, respectively). Men became parents at older ages than women; $35 \%$ of men became a parent between the ages of 25-29 years, while 38\% of women became a parent between the ages of 20-24 years. Regarding the number of living siblings, the proportion was identical between the men and women. Approximately one-fifth of the individuals did not have any siblings, and the largest proportion (33\%) had one sibling. One-fourth of the individuals had two siblings, and a similar proportion had three or more siblings. Regarding the geographic distance from children, the largest category consists of parents whose children mostly lived fewer than $21 \mathrm{~km}$ away (42\% of men and $45 \%$ or women). Regarding the civil status, $69 \%$ of men and $67 \%$ of women were 


\subsection{0}

0.90

0.80

0.70

0.60

0.50

0.40

0.30

0.20

0.10

0.00

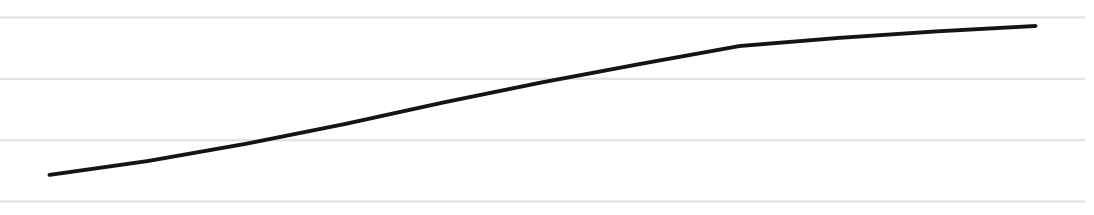

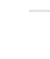

40
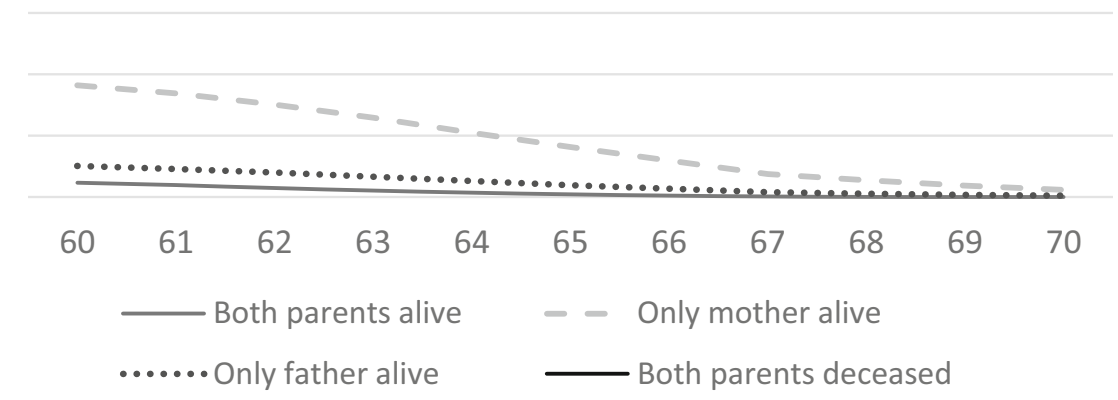

Fig. 1 Proportion of parental vital statuses at the ages 60-70 among men and women pooled (\%)

married, and approximately one-fifth of the individuals was divorced. Women had somewhat higher education levels than the men, with a higher proportion of women than men having tertiary and secondary education (66\% vs. $73 \%$, respectively). Approximately one-third of both men and women lived in metropolitan cities or suburbs of Sweden. Most men and women had not been on sick-leave during the past year; however, more women than men were on sick-leave for more than 2 weeks $(21 \%$ vs. $14 \%$, respectively).

\section{Risk of Retirement by Parental Vital Status}

Table 3 presents the hazard ratios of retirement and confidence intervals based on the complementary log-log models with all control variables included. ${ }^{4}$ In Models 1 and 2 shown in Table 3, the pattern reveals that among men who had only a living mother, there was a $5 \%$ higher risk of retirement, but this increased risk was not found among men who had only a living father compared to those who had both living parents. However, men whose both parents were deceased had a $6 \%$ greater risk of retirement

\footnotetext{
${ }^{4}$ The bivariate and step complementary log-log models with parental status, death of parent(s) and age are presented in Table 1 in the Appendix. The bivariate model separated by gender (Table 1, Appendix) shows the main effects of parental status on retirement transition without controlling for gender. The initial results show that individuals of both genders with only one living parent, particularly a mother, had a greater risk of retiring than individuals with both living parents, and this effect was stronger among the women than the men $(33 \%$ versus $42 \%$ increased risk). The highest risk was observed among those with two deceased parents. Based on our step-wise approach (see Table 1 in Appendix), the effect of parental survival on the risk of retiring substantially decreased after the inclusion of age, which is an indication that most main effects are explained by age.
} 
Table 3 Complementary log-log models with estimated hazard ratios of retirement among Swedish cohorts born between 1940 and 1945 separated by gender

\begin{tabular}{|c|c|c|c|c|c|}
\hline & & \multicolumn{4}{|c|}{ Risk of retirement } \\
\hline & & \multicolumn{2}{|c|}{ Model 1: Men } & \multicolumn{2}{|c|}{ Model 2: Women } \\
\hline & & HR & $95 \% \mathrm{CI}$ & HR & $95 \% \mathrm{CI}$ \\
\hline \multirow[t]{4}{*}{ Parental vital status } & Both parents alive (ref) & 1 & & 1 & \\
\hline & Mother alive, father deceased & 1.05 & $0.99-1.11$ & 1.08 & $1.02-1.14$ \\
\hline & Mother deceased, father alive & 0.99 & $0.94-1.06$ & 1.06 & $1.00-1.14$ \\
\hline & Both mother and father deceased & 1.06 & $1.00-1.11$ & 1.09 & $1.04-1.16$ \\
\hline \multirow{4}{*}{$\begin{array}{l}\text { Recent death of } \\
\text { parent A) }\end{array}$} & No death event (ref) & 1 & & 1 & \\
\hline & Father recently died & 0.99 & $0.96-1.03$ & 1.02 & $0.98-1.06$ \\
\hline & Mother recently died & 1.03 & $1.01-1.06$ & 1.01 & $0.98-1.03$ \\
\hline & Both parents recently died B) & 0.94 & $0.83-1.06$ & 1.12 & $0.99-1.26$ \\
\hline \multirow[t]{5}{*}{ Age } & $60-61$ (ref) & 1 & & 1 & \\
\hline & $62-64$ & 1.44 & $1.42-.146$ & 1.78 & $1.73-1.79$ \\
\hline & 65 & 4.85 & $4.76-4.94$ & 6.66 & $6.53-6.79$ \\
\hline & $66-67$ & 3.01 & $2.94-3.06$ & 3.77 & $3.69-3.86$ \\
\hline & $68-70$ & 0.45 & $0.44-0.47$ & 0.43 & $0.41-0.44$ \\
\hline \multirow[t]{4}{*}{ Siblings } & No siblings & 1.01 & $0.99-1.02$ & 1.01 & $1.00-1.03$ \\
\hline & 1 sibling (ref) & 1 & & 1 & \\
\hline & 2 siblings & 0.97 & $0.96-0.98$ & 0.98 & $0.97-0.99$ \\
\hline & 3 or more siblings & 0.96 & $0.95-0.97$ & 0.97 & $0.96-0.99$ \\
\hline \multirow[t]{4}{*}{ Civil status } & Married (ref) & 1 & & 1 & \\
\hline & Divorced & 0.94 & $0.92-0.95$ & 0.79 & $0.78-0.80$ \\
\hline & Widowed & 1.12 & $1.09-1.16$ & 0.98 & $0.96-0.99$ \\
\hline & Never married & 0.93 & $0.91-0.95$ & 0.82 & $0.81-0.84$ \\
\hline \multirow[t]{5}{*}{ Number of children } & No children & 0.97 & $0.95-0.99$ & 1.06 & $1.04-1.08$ \\
\hline & 1-2 children (ref) & 1 & & 1 & \\
\hline & 3 children & 0.90 & $0.88-0.91$ & 0.90 & $0.88-0.91$ \\
\hline & 4 children & 0.82 & $0.80-0.83$ & 0.82 & $0.79-0.84$ \\
\hline & 5 or more children & 0.74 & $0.72-0.77$ & 0.74 & $0.72-0.78$ \\
\hline \multirow[t]{6}{*}{ Age at first birth } & Below 20 & 1.05 & $1.02-1.09$ & 1.05 & $1.03-1.07$ \\
\hline & $21-24$ & 1 & & 1 & \\
\hline & $25-29$ (ref) & 0.97 & $0.96-0.98$ & 0.96 & $0.95-0.97$ \\
\hline & $30-34$ & 0.87 & $0.85-0.88$ & 0.87 & $0.86-0.89$ \\
\hline & $35-39$ & 0.79 & $0.77-0.81$ & 0.79 & $0.77-0.82$ \\
\hline & 40 or older & 0.73 & $0.71-0.76$ & 0.74 & $0.69-0.79$ \\
\hline \multirow{5}{*}{$\begin{array}{l}\text { Distance to children } \\
\text { C) }\end{array}$} & Majority at close distance (ref) & 1 & & 1 & \\
\hline & Majority at medium distance & 1.05 & $1.03-1.07$ & 1.05 & $1.03-1.07$ \\
\hline & Majority at long distance & 1.06 & $1.04-1.08$ & 1.07 & $1.05-1.08$ \\
\hline & $\begin{array}{l}\text { Some short distance, some medium } \\
\text { distance }\end{array}$ & 0.98 & $0.96-0.99$ & 1.01 & $0.99-1.03$ \\
\hline & $\begin{array}{l}\text { Some short distance, some long } \\
\text { distance }\end{array}$ & 1.00 & $0.98-1.02$ & 1.01 & $0.99-1.03$ \\
\hline
\end{tabular}


Table 3 (continued)

\begin{tabular}{|c|c|c|c|c|c|}
\hline & & \multicolumn{4}{|c|}{ Risk of retirement } \\
\hline & $\begin{array}{l}\text { Some medium distance, some long } \\
\text { distance }\end{array}$ & 1.05 & $1.02-1.08$ & 1.05 & $1.03-1.08$ \\
\hline & At all ranges & 0.98 & $0.95-1.01$ & 0.97 & $0.94-1.00$ \\
\hline & $\begin{array}{l}\text { Missing data regarding all or most } \\
\text { children }\end{array}$ & 1.03 & $1.00-1.07$ & 1.02 & $0.99-1.06$ \\
\hline Grandparenthood & Grandparent & 1.03 & $1.02-1.04$ & 1.05 & $1.04-1.06$ \\
\hline Calendar year & continuous & 1.01 & $1.00-1.01$ & 1.02 & $1.02-1.03$ \\
\hline \multirow[t]{3}{*}{ Education } & Tertiary education & 0.94 & $0.93-0.95$ & 0.88 & $0.87-0.89$ \\
\hline & Secondary education (ref) & 1 & & 1 & $0.87-0.89$ \\
\hline & Primary education & 0.91 & $0.90-0.92$ & 0.98 & $0.97-0.99$ \\
\hline \multirow[t]{2}{*}{ Place of residence } & Metropolitan cities and suburbs & 0.98 & $0.97-0.99$ & 0.96 & $0.95-0.97$ \\
\hline & All other regions & 1 & & 1 & \\
\hline Disposable income & Lagged 1 year & 0.64 & $0.64-0.65$ & 0.69 & $0.69-0.70$ \\
\hline Sick-leave, & No sick-leave (ref) & 1 & & 1 & \\
\hline \multirow[t]{5}{*}{ lagged 1 year } & $1-14$ days & 0.96 & $0.93-0.98$ & 1.02 & $0.99-1.05$ \\
\hline & 15-30 days & 1.07 & $1.03-1.11$ & 1.12 & $1.09-1.16$ \\
\hline & $31-60$ days & 1.21 & $1.18-1.26$ & 1.29 & $1.25-1.33$ \\
\hline & 61-90 days & 1.48 & $1.43-1.54$ & 1.59 & $1.53-1.64$ \\
\hline & $91-365(366)$ days & 3.42 & $3.37-3.46$ & 3.51 & $3.46-3.55$ \\
\hline \multicolumn{2}{|l|}{ Log-likelihood } & \multicolumn{2}{|c|}{$-398,402$} & \multicolumn{2}{|c|}{$-364,235$} \\
\hline \multicolumn{2}{|c|}{ Number of nonzero outcomes } & \multicolumn{2}{|c|}{192,555} & \multicolumn{2}{|c|}{187,388} \\
\hline \multicolumn{2}{|c|}{ Number of observations } & \multicolumn{2}{|c|}{$1,097,512$} & \multicolumn{2}{|c|}{$1,041,529$} \\
\hline
\end{tabular}

A) By "recently died," we mean that the parent or parents died during the year of observation or the preceding year. B) Among those who experienced a retirement transition, 291 men and 311 women had both parents die within the same short period. C) Ranges: close distance $\leq 21 \mathrm{~km}$, medium distance $=21-100 \mathrm{~km}$, long distance $=101+\mathrm{km}$

than those with both living parents. This pattern differed among women, indicating that women had a higher risk of retiring when only their mother ( $8 \%$ higher risk) or only their father (6\% higher risk) was alive than when both parents were living. Additionally, women had a $9 \%$ higher risk of retiring when both parents were deceased than when both were alive. Using our stepwise approach (see Table 7 in Appendix), we found that the main effects of parental vital status on the risk of retiring were strongly weakened by the inclusion of age. Most main effects of parental vital status were explained by age, even after the inclusion of a wide range of control variables, such as education, income, and other kin characteristics. Moreover, the results of the bivariate models of the men and women show similar patterns of parental vital status as the main results, including all control variables shown in Table 3. However, the confidence intervals do not overlap 1 (i.e., are statistically significant) in the bivariate models. In the full models, only the results of the women do not overlap 1 (Model 2 in Table 3). Nonetheless, we found associations between parental vital status and retirement transition at the national level. We also note that differences in the hazard ratios between men and women were small. However, due to small variation in 
parental vital status, we cannot draw firm conclusions from these results. Parental vital status does seem to play a role in retirement transition, however modestly, and the pattern of results indicates groups that are potentially at risk of early retirement. In summary, our results did not support the first hypothesis that individuals who have two living parents have a higher propensity to retire than individuals with two deceased parents. Additionally, as the results showed that women who had one living parent had a higher risk of retirement than women who had both living parents, the second hypothesis that individuals who have one living parent have a higher propensity to retire than those who have two living parents, was confirmed among women. Men exhibited a higher risk of retirement when the mother was alive, but the confidence intervals overlap with 1 .

To determine whether there are gender differences in the retirement risk when one parent is alive (hypothesis 3), we ran an additional model that included an interaction between gender and parental vital status. The recalculated results from the interaction are presented in Table 4, and the supplementary results are included in Table 8 in the Appendix. The results of the interaction showed that compared to men, when both parents were still alive, the risk of retirement is 5\% lower among women. The results also indicated that compared to men, when both parents were deceased, the risk is $9 \%$ greater among women. Additionally, compared to men who had a living mother or father, women had a higher risk of retiring when either their mother or father was still alive, and the risk was slightly higher among women who had only a living father (3\% versus $6 \%$ higher risk of retirement). Hence, the results supported the third hypothesis that women with one living parent have a higher propensity to retire earlier than men with one living parent. In addition, the findings supported the hypothesis that women with a living father have a higher propensity to retire earlier than men with a living father. However, the difference between the hazard ratios was not large, indicating that men's and women's retirement behavior may be more similar than dissimilar in this matter.

In addition to the parental vital status, the previously mentioned Table 3 also presents the risk of retirement during the immediate period after the mother's, father's or both parents' death. Overall, almost all of the results' confidence intervals overlap 1. Hence, we can only present tendencies. The analyses revealed that men whose mother had recently died had a $3 \%$ higher risk of retiring than those without any parents recently die. The pattern among women indicated a marginally higher risk of retiring when either the mother or father had recently died than when neither parent had recently died, but the similarity was greater than the difference. Additionally, the pattern indicated that men had a $6 \%$ lower risk of retiring when both parents had recently died, but women had a $12 \%$ higher risk of retiring.

The association between parental death and retirement transition does not reveal how the "parental constellation" differs at retirement. Hence, by including interactions between parental vital status and death of parent(s) and analyzing men and women separately, we further investigate whether the risk of retiring was greater during the immediate period after parental death than when death occurred some years earlier (hypothesis 4a); we also investigate whether widowed fathers influenced retirement to a greater extent than widowed mothers (Hypothesis $4 \mathrm{~b}$ ). The recalculated hazard ratios are summarized in Table 5, and the supplementary models are presented in Table 9 in 
Table 4 Complementary log-log models with estimated hazard ratios of retirement: Interaction between gender and parental vital status in Swedish cohorts born between 1940 and 1945 (men and women pooled)

\begin{tabular}{|c|c|c|}
\hline & \multicolumn{2}{|c|}{ Risk of retirement } \\
\hline & HR A) & $95 \% \mathrm{CI}$ \\
\hline Both parents alive \# men & 1 & \\
\hline Both parents alive \# women & 0.95 & $0.88-1.02$ \\
\hline Mother alive, father deceased \# men & 1 & \\
\hline Mother alive, father deceased \# women & 1.03 & $1.01-1.05$ \\
\hline Mother deceased, father alive \# men & 1 & \\
\hline Mother deceased, father alive \# women & 1.06 & $1.02-1.11$ \\
\hline Both parents deceased \# men & 1 & \\
\hline Both parents deceased \# women & 1.09 & $1.08-1.10$ \\
\hline
\end{tabular}

Model controlled for age, calendar year, siblings, civil status, number of children, age at first birth, distance to children, grandparenthood, education, place of residence, disposable personal income, and sick-leave. A) Recalculated hazard ratios within each parental status using the reference category "men". See results from the interaction terms in Table 8 in Appendix

the Appendix. Overall, men had a slightly higher risk of retiring when either their mother or father had died some years earlier (i.e., did not die recently) than men whose mother or father had recently died. When both parents had recently died, the retirement risk was 7\% lower among the men, which is also indicated in Model 1 shown in Table 3. Moreover, women had a higher risk of retiring when one of their parents had

Table 5 Complementary log-log models with estimated hazard ratios of retirement: Interaction between parental vital status and death of parent(s) in separate models by gender

\begin{tabular}{|c|c|c|c|c|}
\hline & \multicolumn{4}{|c|}{ Risk of retirement } \\
\hline & \multicolumn{2}{|c|}{ Model 1: Men } & \multicolumn{2}{|c|}{ Model 2: Women } \\
\hline & HR & $95 \% \mathrm{CI}$ & HR & $95 \% \mathrm{CI}$ \\
\hline Mother alive \# father recently $\operatorname{died}^{\text {A) }}$ (ref) & 1 & & 1 & \\
\hline Mother alive \# father did not recently die & 1.03 & $0.94-1.11$ & 0.96 & $0.88-1.04$ \\
\hline Father alive \# mother recently $\operatorname{died}^{\text {A) }}$ (ref) & 1 & & 1 & \\
\hline Father alive \# mother did not recently die & 1.01 & $1.89-1.14$ & 0.94 & $0.83-1.04$ \\
\hline Father alive \# mother recently died ${ }^{\text {A) }}$ (ref) & 1 & & 1 & \\
\hline Mother alive \# father recently died & 1.03 & $0.89-1.17$ & 0.98 & $0.87-1.12$ \\
\hline Both deceased \# no parents recently died (ref) & 1 & & 1 & \\
\hline Both deceased \# father recently died & 1.00 & $0.96-1.04$ & 1.02 & $0.98-1.06$ \\
\hline Both deceased \# mother recently died & 1.04 & $1.01-1.06$ & 1.00 & $0.98-1.02$ \\
\hline Both deceased \# both recently died & 0.93 & $0.84-1.05$ & 1.12 & $0.99-1.26$ \\
\hline
\end{tabular}

Models controlled for age, civil status, number of children, age at first birth, distance to children, grandparenthood, calendar year, education level, disposable personal income, and sick-leave days. Hazard ratios are recalculated; the reference category is marked with (ref). See results from the interaction terms shown in Table 9 in Appendix. A) By "recently died", we mean that the parent or parents died during the year of observation or the preceding year 
been recently widowed, and there was a slightly higher tendency to retire earlier when the father became a widower than when the mother became a widow (6\% versus $4 \%$ ). When both parents had recently died, women had a $12 \%$ higher risk of retiring. However, these women constituted a rather small group (311 women). In the fourth hypothesis, we expected that during the immediate period after the death of one parent, the propensity to retire is greater than if the parent had died some years earlier. This hypothesis was supported only among women. We additionally expected that fathers who recently became widowers would have a stronger impact on their children's retirement transition than mothers who recently became widows, i.e., the propensity to retire is greater when fathers are widowed. The results confirmed this hypothesis among women, although the difference was rather small ( $2 \%$ increased risk). Among the men, mothers who recently became widows had a slightly stronger influence on their sons' retirement than fathers who recently became widowers (3\% increased risk).

As a part of the fourth hypothesis, we also expected that there would be gender differences and given that the propensity to retire is greater during the immediate period after parental death, the propensity to retire should be greater among women than men (hypothesis 4c). To investigate whether this was hypothesis true, we ran a model in which we included a combination variable based on gender, parental vital status and death of parent(s) (and all control variables). In Table 6, we display the observed estimates across equations to detect the gender differences (within categories, men are the reference group). The supplementary models are displayed in Table 10 in Appendix. Overall, the results indicated that compared to men in the same situation, women had a higher risk of retiring during the immediate period after either the father's or mother's death when the other parent was widowed. The association was stronger when the father had recently become widowed (3\% versus $9 \%$ ). In addition, women revealed a $6 \%$ greater risk of retiring when both parents had recently died. In contrast to women, men had a $9 \%$ higher risk of retiring when one of their parents was still alive and the other parent was deceased but had not recently died. Hence, the results supported the hypothesis that the propensity to retire immediately after a parent's death is greater among women than men. In addition to findings supporting our hypothesis, we found that compared to women in the same situation, men had a 5-6\% higher risk of retiring when either the mother or father had recently died and one parent had been a widow/ widower for many years. In contrast to the findings among the women, this association is most likely not explained by caregiving obligations. More consistent with our assumption that women may retire earlier than men because of care obligations, the results revealed that women with both parents deceased but not recently deceased had a $6 \%$ lower risk of retiring than men with both parents deceased but not recently deceased. Additionally, women with both living parents had a $15 \%$ lower retirement risk than men with both living parents.

\section{Siblings as a Moderator}

An aim of our study was to determine whether the presence of siblings moderated the strength of the relationship between parental vital status and risk of retirement. If siblings represent potential alternative or supplemental caregivers, the relationship between the number of siblings and retirement risk should be most strongly negative among those with sole surviving parents, most of whom are likely widowed. To test our 
Table 6 Complementary log-log model with estimated hazard ratios of retirement including a combination variable including gender, parental vital status and death of parent(s) (men and women pooled)

\begin{tabular}{|c|c|c|}
\hline & \multicolumn{2}{|c|}{ Risk of retirement } \\
\hline & HR & $95 \% \mathrm{CI}$ \\
\hline Both parents still alive, none of the parents recently died ${ }^{\mathrm{A}}$ ): men (ref) & 1 & \\
\hline Both parents still alive, none of the parents recently died: women & 0.85 & $0.79-0.92$ \\
\hline Mother still alive, father recently died: men (ref) & 1 & \\
\hline Mother still alive, father recently died: women & 1.03 & $0.92-1.15$ \\
\hline Mother still alive, father deceased but did not recently die: men (ref) & 1 & \\
\hline Mother still alive, father deceased but did not recently die: women & 0.91 & $0.89-0.93$ \\
\hline Father still alive, mother recently died: men (ref) & 1 & \\
\hline Father still alive, mother recently died: women & 1.09 & $0.94-1.26$ \\
\hline Father still alive, mother deceased but did not recently die: men (ref) & 1 & \\
\hline Father still alive, mother deceased but did not recently die: women & 0.91 & $0.87-0.95$ \\
\hline Both parents deceased, none of the parents recently died: men (ref) & 1 & \\
\hline Both parents deceased, none of the parents recently died: women & 0.94 & $0.93-0.95$ \\
\hline Both parents deceased, father recently died: men (ref) & 1 & \\
\hline Both parents deceased, father recently died: women & 0.95 & $0.90-0.99$ \\
\hline Both parents deceased, mother recently died: men (ref) & 1 & \\
\hline Both parents deceased, mother recently died: women & 0.94 & $0.91-0.97$ \\
\hline Both parents deceased, both parents recently died: men (ref) & 1 & \\
\hline Both parents deceased, both parents recently died: women & 1.06 & $0.89-1.24$ \\
\hline
\end{tabular}

Models controlled for age, civil status, number of children, age at first birth, distance to children, grandparenthood, calendar year, education level, disposable personal income, and sick-leave days. Hazard ratios are recalculated, and the reference category is marked with (ref). See results from the interaction term shown in Table 10 in Appendix. A) By "recently died", we mean that the parent or parents died during the year of observation or the preceding year

supposition that caregiving might be responsible for the earlier retirement of women with one surviving parent, we stratified the model for men and women separately by the number of siblings and observed the parental vital status estimates across equations. These estimates are presented in Table 11 in the Appendix, and the predicted hazard ratios of the various parental conditions are shown in Fig. 2. Overall, the interactions are not statistically significant, but since we use data including the whole population it is still possible to distinguish patterns. As shown in the figure, both men and women with a surviving father (deceased mother) and one sibling had the steepest decrement in retirement risk as a function of having additional siblings. The pattern among those with a surviving mother (father deceased) was similar but not as severe. We also find that women without siblings have the highest risk of retiring. In summary, individuals with parents, especially fathers, experiencing vulnerability due to widowhood show a tendency to retire earlier if they were from smaller families; although this finding was not statistically significant, it is consistent with the caregiving explanation. Furthermore, the increase in the retirement risk as a function of having fewer siblings was most noticeable among women with a sole surviving father, who might be considered 


\section{1}

1.05
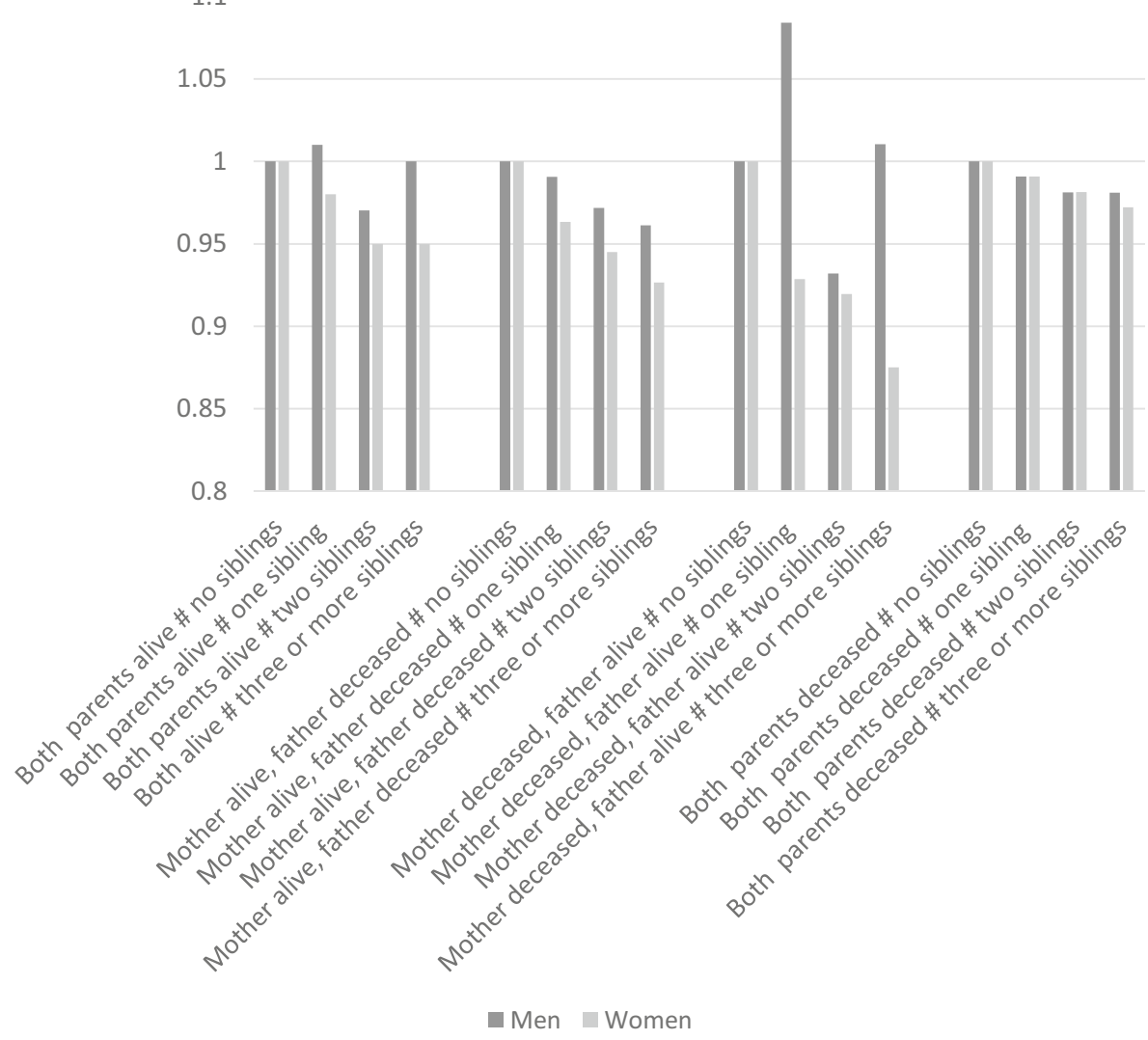

Fig. 2 Predicted hazard ratios of the retirement risk by parental vital status and number of siblings in separate models by gender. Note: Models controlled for age, civil status, number of children, age at first birth, distance to children, grandparenthood, calendar year, education level, disposable personal income, and sick-leave days. See results from the interaction terms shown in Table 10 in Appendix

particularly vulnerable given the known gender differences in the experience of adverse risks following widowhood. In summary, the patterns found confirmed the final two hypotheses, i.e., the absence of siblings strengthens the relationship between parental death and risk of retirement, and that finding is particularly true among women as they are more frequently the caregivers of their elderly parents than men.

\section{Robustness Assessment}

As most individuals in this study population had two deceased parents once they approached retirement age, we performed robustness analyses to examine whether the results persist when this specific group was excluded in models identical to the models shown in Table 3. The results of the parental vital status, death of parent(s) and number of siblings are presented in Table 12 in the Appendix. Overall, the gender pattern remained the same as that shown in the results in Table 3, increasing our confidence in our main results. Particularly, the results showed that among men who had a living mother, the risk of retirement statistically significantly differed from that 
among men who had both living parents (4\% higher risk), and among women, having either a living mother or living father was statistically significant (5\% in both situations). The results also showed that increasing the number of siblings statistically significantly reduced the risk of retirement among both men and women and that women had a 5\% higher risk of retiring when they did not have siblings. Moreover, we additionally included an interaction between the number of siblings and parental vital status in the restricted population with at least one living parent (models not presented). The results show very similar results as presented in the models with the full population.

\section{Summary and Discussion}

The present study highlights the connection between the following two important social issues confronting most developed societies: the transition to retirement and serving the needs of an expanding older population. Our analysis of population data from Sweden reveals several interesting results regarding how the parental vital status is associated with the retirement transition. Before proceeding with the discussion, it is important for understanding the implications of the study's findings, that the influence of parental vital status on retirement transitions was measurable but overall minor. However, the findings are robust to the inclusion of numerous control variables and sensitivity analyses, lending confidence to the conclusion that parental vital status has an independent, but relatively small, influence on retirement transitions. As Sweden has generous welfare services, including extensive elderly care, it is unsurprising that the effect is minor. However, the magnitude of parental vital status is similar to that of other factors significant for retirement transition, such as being tertiary educated, childless, divorced or a grandparent. This study observes an entire population, rendering any discussion of statistically significant results less meaningful. Nonetheless, the lack of statistically significant results can be explained by the large proportion of individuals with both parents deceased. Analyses using a restricted population produced similar results as those using the full population, lending additional credibility to our findings. Nevertheless, it is important that the reader is aware of these issues and approaches our discussion with some caution.

We first hypothesized that compared to having two deceased parents, having two living parents would increase the risk of retirement. The findings did not support this hypothesis, even after including age. However, having two deceased parents increased the risk of retirement, especially among women. The higher risk of retirement among individuals with deceased parents may be explained by the generational transmission of health and socioeconomic status. For example, individuals whose parents died at younger ages might have poor health or a low socioeconomic status, which are also strongly related to early retirement. Another potential explanation is that the loss of both parents may trigger retirement because of caregiving, which may have recently occurred if the surviving parents experienced a period of frailty before death. Additionally, the transition from caregiving may present the opportunity to disengage from both formal and informal labor. These findings also echo earlier studies, which have shown that the experience of parental death may lead to adverse health consequences and decreases in life satisfaction in children up to several years after the parental death, 
particularly among women (Leopold and Lechner 2015; Umberson 2003). After parental death, younger adults could perhaps choose to go on sick-leave, whereas adults approaching retirement age may instead choose to retire.

Moreover, this study provides evidence that individuals with one living parent have a higher risk of retiring, and the pattern was the strongest among women who had a living father. We also hypothesized that the propensity to retire would be higher during the immediate period after parental death. Indeed, this study revealed that the risk of retirement is higher during the immediate period after parental death, especially when the father becomes a widower. Consistent with the findings reported by Bolin et al. (2008), this study also finds that parents influence men's labor force attachment; in particular, men have a higher risk of retiring when either their mother or father, who had been widowed for some years, has recently died or if either parent is still alive but has been widowed for some years. These findings do not necessarily support our assumptions of care obligations. The different patterns between the men and women in this study may be an indication of the different motivations sons and daughters have to provide support and care to their older parents (Silverstein et al. 1995). Moreover, the patterns of how siblings strengthen the relationship between parental death and the risk of retirement mainly showed that the risk of retirement was greater among individuals without siblings either with both living parents or only a living mother or father, and the pattern was most noticeable among women.

Furthermore, the finding that the relationship between surviving parents and retirement transition is more evident and robust among women, particularly among women without siblings whose parents recently died, supports the conclusion that providing care for parents specifically motivates labor force disengagement in the form of retirement. Previous studies have found that mainly daughters care for their elderly parents and that they may reduce their employment to provide that care.

Our analysis also takes advantage of multiple aspects of family availability to predict retirement transition. Consistent with the linked-lives principle of the life course perspective, we found that the retirement risk is greater among those with fewer children, who are younger at the birth of the first child, and who live at a greater geographic distance from their children. These conditions reflect opportunities for family integration and constraints of family obligation that enhance the decision to exit the labor force.

Several limitations of this study should be mentioned. First, the birth cohort studied entered the labor force and subsequently retired during a historically prosperous era in Sweden and may not be indicative of future cohorts who are facing greater austerity in government programs. In addition, our results are representative of average effects over the study period. Indeed, the increased health of the oldest old may reduce the need for adult children to retire to care for aged parents, and the reductions in the Swedish health and social care systems may induce adult children to retire to care for aged parents. These counteracting trends occurring during the study interval each suggests that the results reported may be stronger or weaker during different segments of the 13 years observed.

Second, while we excluded immigrants from our analyses, immigrant groups, many of whom are from traditional cultures, will represent an increasing proportion of the 
workforce and retirees. To the extent that cultural factors play a role in work-family decisions, future cohorts may be increasingly sensitive to the demands imposed by work roles. These future cohorts of workers will also be likely to have parents surviving to older ages, creating more acute considerations in future retirement decisions.

Third, we observe individuals from the age of 60; thus, some individuals might have already left the labor market to care for their elderly parents. However, only a small proportion of people in Sweden retire before the age of 60 for reasons other than health limitations.

Fourth, we caution against a causal interpretation of our results. There exists the possibility that unobserved factors common to parental vital status and retirement guided the selection of individuals into retirement. The most likely candidate factor is poor health status, which, we note, is controlled by a measure of sick-leave days. Nevertheless, we recognize that this an incomplete measure of health and endogeneity related to family-wide risk factors may not be fully mitigated.

Fifth, we do not know the extent to which the index persons had contact with or provided assistance to their parents. However, the literature suggests that strong supportive relationships exist between younger and older generations in Sweden, even compared to other European countries (Brandt et al. 2009). Thus, it is reasonable to assume that a large proportion of adult children provide support to their older parents. Our incorporation of sibling availability into the model serves as a proof-of-concept and, at a minimum, is consistent with our interpretation that kinship dynamics of contact and care are responsible for our results.

Finally, the question of whether our results are generalizable beyond the nation of Sweden is reasonable given the elaborate nature of Swedish welfare state provisions. This aspect of Swedish society provides a stringent test of our hypotheses, which implicitly invoke family care as an underlying mechanism. Furthermore, the relatively generous pension system in Sweden provides a good context in which to investigate the social antecedents of retirement, which is arguably less inhibited by economic necessity and more likely to be enhanced by social considerations than possible in other nations.

We conclude that the presence of aging parents seems to play a role in when their adult children retire from the labor force. However, we can also conclude that the marginally increased risk of retirement among those with parents alive does not count among the most important predictors of retirement in Sweden. Nonetheless, based on reliable data about the Swedish population obtained from linked registries, we observe a measurable connection between the presence of older generations and the following generation's decision to retire. Whether the demands for care serve as an explanation of our results remains speculative, but this hypothesis is based on the robustness of the interactions between parents' vital status and sibling availability. Our findings also suggest that women entering old age, who already represent a vulnerable group with respect to pensions and earnings, are further disadvantaged by perhaps prematurely leaving the workforce to care for their parents. We recommend that future research delve more deeply into the microdynamics of family life to tease out nuanced explanations of these interconnected demographic processes. 


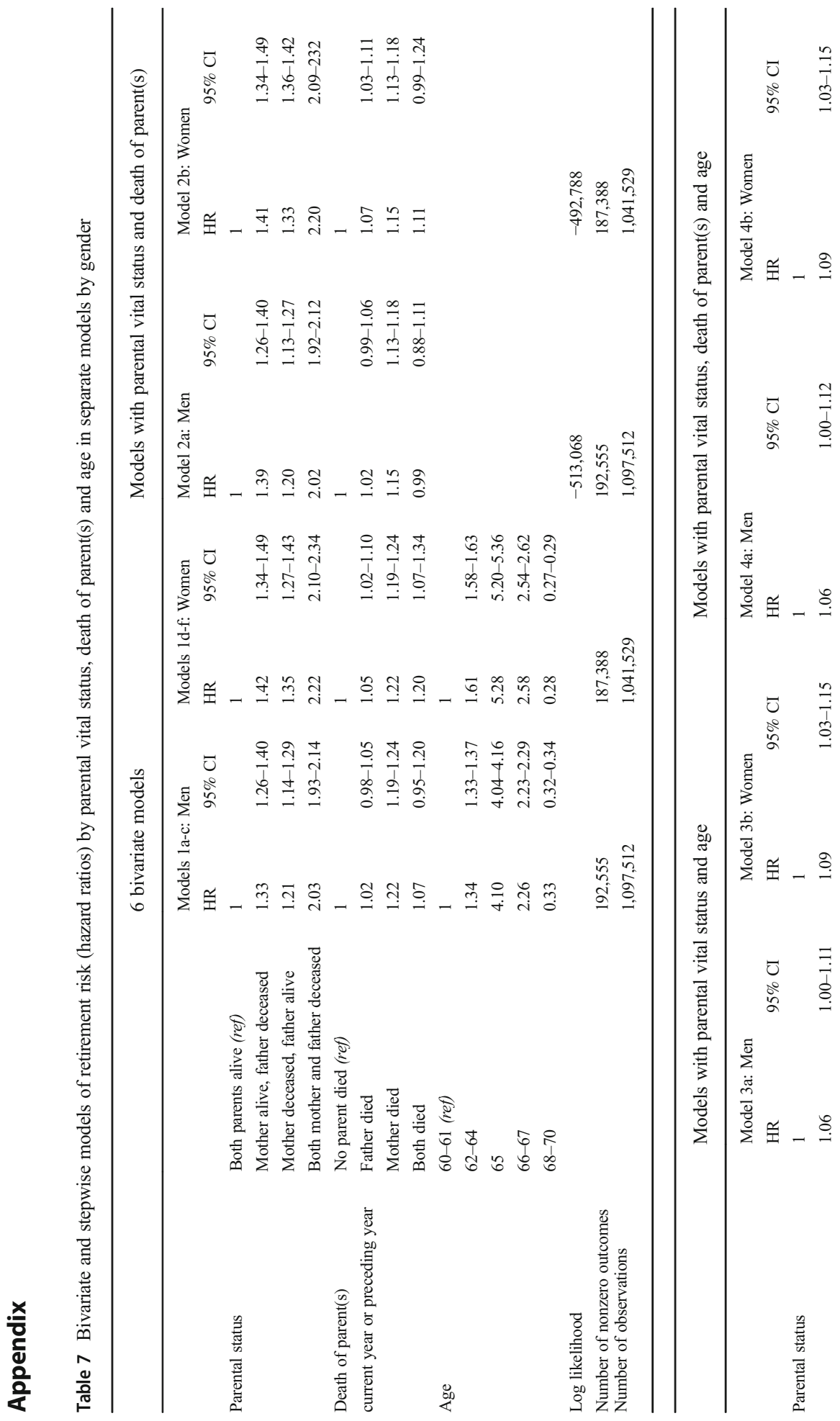




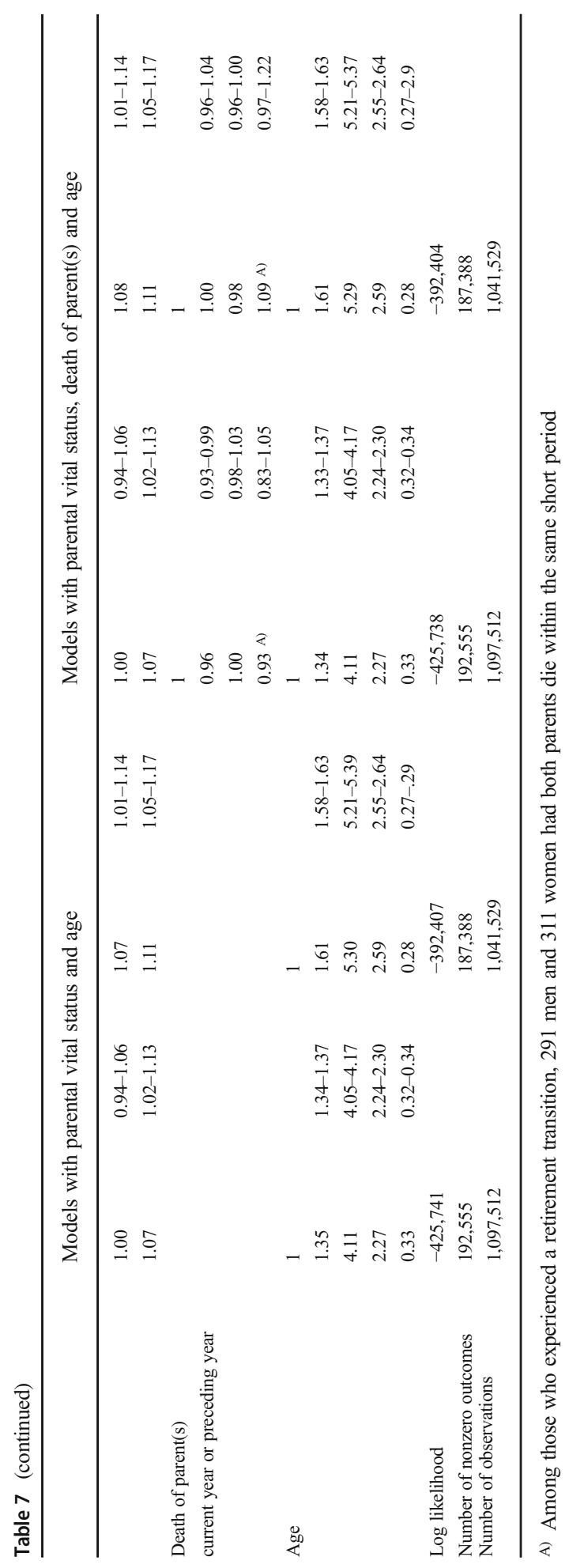


Table 8 Complementary log-log models with estimated hazard ratios of retirement: Interaction between gender and parental vital status in Swedish cohorts born between 1940 and 1945 (men and women pooled)

Risk of retirement

HR $95 \% \mathrm{CI}$

Both parents alive \# men (ref)

\section{1}

0.95

$0.88-1.03$

Both parents alive \# women

1.03

0.98-1.09

Mother alive, father deceased \# women

1.06

$1.00-1.12$

Mother deceased, father alive \# men

0.98

$0.93-1.04$

Mother deceased, father alive \# women

1.04

$0.98-1.11$

Both parents deceased \# men

1.02

$0.97-1.08$

Both parents deceased \# women

1.11

$1.06-1.17$

Log likelihood

$-818,678$

Number of nonzero outcomes

379,943

Number of observations

$1,202,041$

Model controlled for age, calendar year, siblings, civil status, number of children, age at first birth, distance to children, grandparenthood, education, place of residence, disposable personal income, and sick-leave days

Table 9 Complementary log-log models with interaction between parental vital status and death of parent(s) in separate models by gender

Risk of retirement

\begin{tabular}{lllll}
\hline \multirow{2}{*}{ Model 1: Men } & & & \multicolumn{2}{l}{ Model 2: Women } \\
\cline { 1 - 1 } \cline { 5 - 5 } HR & $95 \%$ CI & & HR & $95 \%$ CI \\
1 & & 1 & \\
1.05 & $0.99-1.11$ & & 1.08 & $1.02-1.14$ \\
1.02 & $0.92-1.12$ & & 1.13 & $1.02-1.24$ \\
1.01 & $0.94-1.06$ & & 0.08 & $1.00-1.13$ \\
0.99 & $0.87-1.13$ & & 1.14 & $1.02-1.28$ \\
1.06 & $1.00-1.11$ & & 1.10 & $1.04-1.16$ \\
1.06 & $0.99-1.13$ & & 1.11 & $1.04-1.19$ \\
1.10 & $1.04-1.16$ & & 1.10 & $1.03-1.16$ \\
0.99 & $0.87-1.13$ & & 1.23 & $1.08-1.39$ \\
$-398,401$ & & & $-364,235$ & \\
192,555 & & & 187,388 & \\
$1,097,512$ & & $1,041,529$ &
\end{tabular}

Model controlled for age, calendar year, siblings, civil status, number of children, age at first birth, distance to children, grandparenthood, education, place of residence, disposable personal income, and sick-leave days 
Table 10 Complementary log-log model with a combination variable encompassing gender, parental vital status and death of parent(s) among men and women pooled

\begin{tabular}{|c|c|c|}
\hline & \multicolumn{2}{|c|}{ Risk of retirement } \\
\hline & HR & $95 \% \mathrm{CI}$ \\
\hline Both parents alive, no parent recently died: men & 0.99 & $0.94-1.05$ \\
\hline Both parents alive, no parent recently died: women & 0.84 & $0.79-0.89$ \\
\hline Mother alive, father recently died: men & 0.98 & $0.90-1.07$ \\
\hline Mother alive, father recently died: women & 1.01 & $0.93-1.09$ \\
\hline Mother alive, father did not recently die: men (ref) & 1 & \\
\hline Mother alive, father did not recently die: women & 0.91 & $0.89-0.92$ \\
\hline Father alive, mother recently died: men & 0.95 & $0.85-1.06$ \\
\hline Father alive, mother recently died: women & 1.03 & $0.93-1.14$ \\
\hline Father alive, mother did not recently die: men & 1.00 & $0.97-1.03$ \\
\hline Father alive, mother did not recently die: women & 0.91 & $0.88-0.94$ \\
\hline Both deceased, no parent recently died: men & 0.97 & $0.95-0.98$ \\
\hline Both deceased, no parent recently died: women & 0.91 & $0.89-0.92$ \\
\hline Both deceased, father recently died: men & 1.03 & $0.98-1.07$ \\
\hline Both deceased, father recently died: women & 0.98 & $0.93-1.02$ \\
\hline Both deceased, mother recently died: men & 1.02 & $0.99-1.04$ \\
\hline Both deceased, mother recently died: women & 0.95 & $0.93-0.98$ \\
\hline Both deceased, both parents recently died: men & 0.99 & $0.88-1.12$ \\
\hline Both deceased, both parents recently died: women & 1.05 & $0.94-1.17$ \\
\hline Log likelihood & $-1,193,059$ & \\
\hline Number of nonzero outcomes & 379,943 & \\
\hline Number of observations & $4,719,148$ & \\
\hline
\end{tabular}

Model controlled for age, calendar year, siblings, civil status, number of children, age at first birth, distance to children, grandparenthood, education, place of residence, disposable personal income, and sick-leave days 
Table 11 Complementary log-log models with interaction between parental vital status and number of siblings in separate models by gender

\begin{tabular}{|c|c|c|c|c|}
\hline & \multicolumn{4}{|c|}{ Risk of retirement } \\
\hline & \multicolumn{2}{|c|}{ Model 1: Men } & \multicolumn{2}{|c|}{ Model 2: Women } \\
\hline & HR & $95 \% \mathrm{CI}$ & HR & $95 \% \mathrm{CI}$ \\
\hline Both parents alive \# no siblings (ref) & 1 & & 1 & \\
\hline Both parents alive \# one sibling & 1.01 & $0.86-1.19$ & 0.98 & $0.83-1.16$ \\
\hline Both parents alive \# two siblings & 0.98 & $0.83-1.17$ & 0.95 & $0.79-1.14$ \\
\hline Both parents alive \# three or more siblings & 0.98 & $0.83-1.17$ & 0.95 & $0.79-1.13$ \\
\hline Mother alive, father deceased \# no siblings & 1.07 & $0.93-1.24$ & 1.09 & $0.94-1.26$ \\
\hline Mother alive, father deceased \# one sibling & 1.06 & $0.92-1.22$ & 1.05 & $0.91-1.22$ \\
\hline Mother alive, father deceased \# two siblings & 1.03 & $0.89-1.18$ & 1.03 & $0.89-1.19$ \\
\hline Mother alive, father deceased \# three or more siblings & 0.99 & $0.86-1.14$ & 1.01 & $0.87-1.16$ \\
\hline Mother deceased, father alive \# no siblings & 0.95 & $0.81-1.11$ & 1.12 & $0.96-1.32$ \\
\hline Mother deceased, father alive \# one sibling & 1.03 & $0.88-1.19$ & 1.04 & $0.89-1.20$ \\
\hline Mother deceased, father alive \# two siblings & 0.96 & $0.83-1.11$ & 1.03 & $0.88-1.19$ \\
\hline Mother deceased, father alive \# three or more siblings & 0.97 & $0.84-1.13$ & 0.98 & $0.84-1.14$ \\
\hline Both parents deceased \# no siblings & 1.08 & $0.94-1.24$ & 1.08 & $0.94-1.25$ \\
\hline Both parents deceased \# one sibling & 1.07 & $0.93-1.23$ & 1.07 & $0.93-1.24$ \\
\hline Both parents deceased \# two siblings & 1.05 & $0.90-1.19$ & 1.06 & $0.91-1.22$ \\
\hline Both parents deceased \# three or more siblings & 1.03 & $0.90-1.19$ & 1.05 & $0.91-1.21$ \\
\hline Log likelihood & $-414,478$ & & -380 & \\
\hline Number of nonzero outcomes & 192,555 & & 187,3 & \\
\hline Number of observations & $1,097,512$ & & 1,041 & \\
\hline
\end{tabular}

Models controlled for age, calendar year, siblings, civil status, number of children, age at first birth, distance to children, grandparenthood, education, place of residence, disposable personal income, and sick-leave days 
Table 12 Complementary log-log models with estimated hazard ratios of retirement among Swedish cohorts born between 1940 and 1945 with at least one living parent in separate models by gender

\begin{tabular}{|c|c|c|c|c|c|}
\hline & & \multicolumn{4}{|c|}{ Risk of retirement } \\
\hline & & \multicolumn{2}{|c|}{ Model 1: Men } & \multicolumn{2}{|c|}{ Model 2: Women } \\
\hline & & $\mathrm{HR}$ & $95 \% \mathrm{CI}$ & $\mathrm{HR}$ & $95 \% \mathrm{CI}$ \\
\hline \multirow[t]{3}{*}{ Parental status } & Both parents alive (ref) & 1 & & 1 & \\
\hline & Mother alive, father deceased & 1.04 & $1.01-1.07$ & 1.05 & $1.01-1.09$ \\
\hline & Mother deceased, father alive & 0.99 & $0.93-1.05$ & 1.05 & $1.01-1.10$ \\
\hline \multirow[t]{3}{*}{ Recent death of parent } & No parent died (ref) & 1 & & 1 & \\
\hline & Father recently died & 0.97 & $0.89-1.06$ & 1.04 & $0.95-1.12$ \\
\hline & Mother recently died & 0.98 & $0.88-1.11$ & 1.05 & $0.94-1.17$ \\
\hline \multirow[t]{4}{*}{ Siblings } & No siblings & 0.99 & $0.95-1.03$ & 1.05 & $1.01-1.09$ \\
\hline & 1 sibling (ref) & 1 & & 1 & \\
\hline & 2 siblings & 0.95 & $0.92-0.99$ & 0.97 & $0.94-1.01$ \\
\hline & 3 or more siblings & 0.94 & $0.91-0.97$ & 0.95 & $0.92-0.98$ \\
\hline \multicolumn{2}{|l|}{ Log likelihood } & \multicolumn{2}{|c|}{$-62,521$} & \multicolumn{2}{|c|}{$-57,514$} \\
\hline \multirow{2}{*}{\multicolumn{2}{|c|}{$\begin{array}{l}\text { Number of nonzero outcomes } \\
\text { Number of observations }\end{array}$}} & \multicolumn{2}{|c|}{24,865} & \multicolumn{2}{|c|}{24,258} \\
\hline & & \multicolumn{2}{|c|}{202,416} & \multicolumn{2}{|c|}{195,502} \\
\hline
\end{tabular}

Models controlled for age, calendar year, siblings, civil status, number of children, age at first birth, distance to children, grandparenthood, education, place of residence, disposable personal income, and sick-leave days

Open Access This article is distributed under the terms of the Creative Commons Attribution 4.0 International License (http://creativecommons.org/licenses/by/4.0/), which permits unrestricted use, distribution, and reproduction in any medium, provided you give appropriate credit to the original author(s) and the source, provide a link to the Creative Commons license, and indicate if changes were made.

\section{References}

Albertini, M., Kohli, M., \& Vogel, C. (2007). Intergenerational transfers of time and money in European families: Common patterns - Different regimes? Journal of European Social Policy, 17(4), 319-334.

Allison, P. D. (2010). Survival analysis using SAS: A practical guide (2nd ed.).

Barnes-Farell, J. L. (2003). Beyond health and wealth: Attitudinal and other influences on retirement decisionmaking. In G. Adams \& T. Beehr (Eds.), Retirement: Reasons, processes and results (pp. 159-187). New York: Springer.

Blekesaune, M., \& Solem, P. E. (2005). Working conditions and early retirement: A prospective study of retirement behavior. Research on Aging, 27(1), 3-30.

Bolin, K., Lindgren, B., \& Lundborg, P. (2008). Your next of kin or your own career? Journal of Health Economics, 27(3), 718-738. https://doi.org/10.1016/j.jhealeco.2007.10.004.

Brandt, M., Haberkern, K., \& Szydlik, M. (2009). Intergenerational help and Care in Europe. European Sociological Review, 25(5), 585-601.

Campbell, L. D., \& Martin-Matthews, A. (2003). The gendered nature of Men's filial care. The Journals of Gerontology: Series B, 58(6), S350-S358.

Coneus, K., \& Spiess, C. K. (2012). The intergenerational transmission of health in early childhoodEvidence from the German socio-economic panel study. Economics \& Human Biology, 10(1), 89-97.

Daatland, S. O., \& Lowenstein, A. (2005). Intergenerational solidarity and the family-welfare state balance. European Journal of Ageing, 2(3), 174-182. 
Dentinger, E., \& Clarkberg, M. (2002). Informal caregiving and retirement timing among men and women: Gender and caregiving relationships in late midlife. Journal of Family Issues, 23(7), 857-879.

Doty, P. (1995). Family caregiving and access to publicly funded home care. In R. A. Kane \& J. D. Penrod (Eds.), Family caregiving in an aging society (pp. 92-122). Thousand Oaks: Sage.

Drobnič, S. (2002). Retirement timing in Germany. International Journal of Sociology, 32(2), 75-102.

Duval, R. (2003). The Retirement Effects of Old-Age Pension and Early Retirement Schemes in OECD Countries. OECD Economics Department Working Papers. No. 370, OECD Publishing, Paris. Retrieved from http://www.oecd-ilibrary.org/content/workingpaper/308728704511. Accessed 14 Mar 2019.

Eggebeen, D. J. (1992). Family structure and intergenerational exchanges. Research on Aging, 14(4), 427-447.

Elder, G. H. J., Johnson, M. K., \& Crosnoe, R. (2003). The emergence and development of life course theory. In J. T. Mortimer \& M. J. Shanahan (Eds.), Handbook of the Life Course (pp. 3-19). Springer US.

Elstad, J. I. (2005). Childhood adversities and health variations among middle-aged men: A retrospective lifecourse study. European Journal of Public Health, 15(1), 51-58. https:/doi.org/10.1093/eurpub/cki114.

Feldman, D. C., \& Beehr, T. A. (2011). A three-phase model of retirement decision making. American Psychologist, 66(3), 193-203.

Flood, L. (2007). Can we afford the future? An evaluation of the new Swedish pension system. In A. Harding \& A. Gupta (Eds.), Modelling our future. Population ageing, social security and taxation. Oxford: Elsevier.

Gruber, J., \& Wise, D. A. (1999). Social security programs and retirement around the world. Research in Labor Economics, 1(18), 1-40.

Hank, K., \& Buber, I. (2009). Grandparents caring for their grandchildren: Findings from the 2004 survey of health, ageing, and retirement in Europe. Journal of Family Issues, 30(1), 53-73.

Hartig, T., \& Fransson, U. (2006). Housing tenure and early retirement for health reasons in Sweden. Scandinavian Journal of Public Health, 34(5), 472-479.

Hatch, L. R., \& Thompson, A. (1992). Family responsibilities and Women's retirement. In Families and Retirement Family Responsibilities and Women's Retirement. Thousand Oaks: SAGE Publications.

Hayward, M. D., Friedman, S., \& Chen, H. (1998). Career trajectories and older men's retirement. The Journals of Gerontology Series B: Psychological Sciences and Social Sciences, 53(2), S91-S103.

Higgs, P., Mein, G., Ferrie, J., Hyde, M., \& Nazroo, J. (2003). Pathways to early retirement: structure and agency in decision-making among British civil servants. Ageing \& Society, 23(6), 761-778.

Himes, C. L. (1994). Parental caregiving by adult women: A demographic perspective. Research on Aging, 16(2), 191-211. https://doi.org/10.1177/0164027594162004.

Hochman, O., \& Lewin-Epstein, N. (2013). Determinants of early retirement preferences in Europe: The role of grandparenthood. International Journal of Comparative Sociology, 54(1), 29-47.

Johansson, P., Laun, L., \& Palme, M. (2014). Pathways to Retirement and the Role of Financial Incentives in Sweden (working paper no. 20123). National Bureau of Economic Research.

Josephson, M., Lindberg, P., Voss, M., Alfredsson, L., \& Vingård, E. (2008). The same factors influence job turnover and long spells of sick leave-A 3-year follow-up of Swedish nurses. European Journal of Public Health, 18(4), 380-385.

Karpansalo, M., Kauhanen, J., Lakka, T. A., Manninen, P., Kaplan, G. A., \& Salonen, J. T. (2005). Depression and early retirement: Prospective population based study in middle aged men. Journal of Epidemiology \& Community Health, 59(1), 70-74.

Kim, S., \& Feldman, D. C. (2000). Working in retirement: The antecedents of bridge employment and its consequences for quality of life in retirement. Academy of Management Journal, 43(6), 1195-1210.

Kridahl, L. (2015). Retirement and Leisure: A longitudinal Study using Swedish Data. In A. FürnkranzPrskawetz, M. Kuhn, and U. Sunde (Eds.), Vienna Yearbook of Population Research 2014 (pp. 141-168). Austria: Austrian Academy of Sciences Press.

Kridahl, L., \& Kolk, M. (2018). Retirement coordination in opposite-sex and same-sex married couples: Evidence from Swedish registers. Advances in Life Course Research., 38, 22-36.

Leopold, T., \& Lechner, C. M. (2015). Parents' death and adult well-being: Gender, age, and adaptation to filial bereavement. Journal of Marriage and Family, 77(3), 747-760.

Lilly, M. B., Laporte, A., \& Coyte, P. C. (2007). Labor market work and home Care's unpaid caregivers: A systematic review of labor force participation rates, predictors of labor market withdrawal, and hours of work. Milbank Quarterly, 85(4), 641-690.

McGarry, K. (2004). Health and retirement do changes in health affect retirement expectations? Journal of Human Resources, XXXIX(3), 624-648.

Moen, P., Robison, J., \& Fields, V. (1994). Women's work and caregiving roles: A life course approach. Journal of Gerontology, 49(4), S176-S186. 
O'Rand, A. M., \& Henretta, J. C. (1999). Age and inequality: Diverse pathways through later life. Boulder: Westview Press.

OECD. (2017). Average effective age of retirement. OECD. Retrieved from http://www.oecd. org/els/emp/average-effective-age-of-retirement.htm. Accessed 14 Mar 2019.

OECD. (2019). "Labour Market Statistics: Labour force statistics by sex and age: indicators", OECD Employment and Labour Market Statistics (database), https://stats.oecd.org/viewhtml.aspx?datasetcode= LFS_SEXAGE_I_R\&lang=en. Accessed 14 Mar 2019.

Ogg, J., \& Renaut, S. (2006). The support of parents in old age by those born during 1945-1954: A European perspective. Ageing \& Society, 26(5), 723-743.

Palme, M., \& Svensson, I. (1999). Social security, occupational pensions, and retirement in Sweden. In J. Gruber \& D. A. Wise (Eds.) (pp. 355-402). Chicago: University of Chicago Press.

Palme, M., \& Svensson, I. (2004). Income security programs and retirement in Sweden. In I. Gruber \& D. A. Wise (Eds.), Social security programs and retirement around the world: Micro-estimation (pp. 579-641). Chicago: University of Chicago Press.

Radl, J. (2013). Labour market exit and social stratification in Western Europe: The effects of social class and gender on the timing of retirement. European Sociological Review, 29(3), 654-668.

Raymo, J. M., \& Sweeney, M. M. (2006). Work-family conflict and retirement preferences. The Journals of Gerontology: Series B, 61(3), S161-S169.

Roan, C. L., \& Raley, R. K. (1996). Intergenerational Coresidence and contact: A longitudinal analysis of adult Children's response to their Mother's widowhood. Journal of Marriage and Family, 58(3), 708-717.

Sell, L. (2009). Predicting long-term sickness absence and early retirement pension from self-reported work ability. International Archives of Occupational and Environmental Health, 82(9), 1133-1138.

Silverstein, M., \& Bengtson, V. L. (1994). Does intergenerational social support influence the psychological well-being of older parents? The contingencies of declining health and widowhood. Social Science \& Medicine, 38(7), 943-957.

Silverstein, M., Parrott, T. M., \& Bengtson, V. L. (1995). Factors that predispose middle-aged sons and daughters to provide social support to older parents. Journal of Marriage and Family, 57(2), 465-475.

Sjögren Lindquist, G. S., \& Wadensjö, E. (2009). Retirement, pensions and work in Sweden. The Geneva Papers on Risk and Insurance - Issues and Practice, 34(4), 578-590.

Soldo, B. J., \& Myllyluoma, J. (1983). Caregivers who live with dependent elderly. The Gerontologist, 23(6), 605-611.

Statistics Sweden. (2003). Migration flows in Sweden 1991-2001. Demografi ska rapporter 2003:2. Örebro.

Statistics Sweden. (2011). Theme: Pensioners; Transition from working life to retirement. (theme Report No. 2011:2)

Statistics Sweden. (2014). Demographic reports 2014:2 Generations through the years - a demographic description of those born during the 20th century. Retrieved from http://www.scb.se/Statistik/_ Publikationer/BE0701_2014A01_BR_BE51BR1402.pdf

Statistics Sweden. (2018). Sveriges framtida befolkning 2018-2070. Demografiska rapporter 2018:1. [the future population of Sweden 2018-2070. Demographic reports 2018:1].

Stoller, E. P., Forster, L. E., \& Duniho, T. S. (1992). Systems of Parent Care within sibling networks. Research on Aging, 14(1), 28-49.

Stueve, A., \& O'Donnell, L. (1989). Interactions between women and their elderly parents: Constraints of daughters' employment. Research on Aging, 11(3), 331-353. https://doi.org/10.1177/0164027589113004.

Sundén, A. (2006). The Swedish experience with pension reform. Oxford Review of Economic Policy, 1, $133-148$.

Sundström, G. (2009). Demography of aging in the Nordic countries. In International Handbook of Population Aging (pp. 91-111). Dordrecht: Springer.

Sundström, G., Johansson, L., \& Hassing, L. B. (2002). The shifting balance of long-term Care in Sweden. The Gerontologist, 42(3), 350-355.

Sundström, G., Malmberg, B., \& Johansson, L. (2006). Balancing family and state care: Neither, either or both? The case of Sweden. Ageing \& Society, 26(5), 767-782.

Svensson, I., Lundholm, E., De Luna, X., \& Malmberg, G. (2015). Family life course and the timing of Women's retirement - A sequence analysis approach. Population, Space and Place, 21(8), 856-871.

Swedish Social Insurance Agency. (2005). The Swedish Pension System Annual Report 2004. National insurance agency 2005: National insurance agency.

Szebehely, M. (1999). Omsorgsarbetets olika former: Nya klasskillnader och gamla könsmönster i äldreomsorgen / changing forms of care work: New class distinctions and old gender patterns in care for the elderly. Sociologisk Forskning, 36(1), 7-32.

Szebehely, M., \& Trygdegård, G.-B. (2012). Home care for older people in Sweden: A universal model in transition. Health \& Social Care in the Community, 20(3), 300-309. 
Szebehely, M., \& Ulmanen, P. (2009). Att ge omsorg till gamla föräldrar och andra anhöriga: påverkar det relationen till arbetsmarknaden? [Caregiving to elderly parents and other relatives: does it affect the relation to the labour market?]. Npublished report. Stockholm: Ministry of Health and Social Affairs.

Szinovacz, M. E., \& Deviney, S. (2000). Marital characteristics and retirement decisions. Research on Aging, 22(5), 470-498. https://doi.org/10.1177/0164027500225002.

Szinovacz, M. E., DeViney, S., \& Davey, A. (2001). Influences of family obligations and relationships on retirement variations by gender, race, and marital status. The Journals of Gerontology: Series B, 56(1), S20-S27.

Ulmanen, P. (2013). Working daughters: A blind spot in Swedish eldercare policy. Social Politics: International Studies in Gender, State \& Society, 20(1), 65-87.

Ulmanen, P., \& Szebehely, M. (2015). From the state to the family or to the market? Consequences of reduced residential eldercare in Sweden. International Journal of Social Welfare, 24(1), 81-92.

Umberson, D. (2003). Death of a parent: Transition to a new adult identity. New York: Cambridge University Press.

Umberson, D., Wortman, C. B., \& Kessler, R. C. (1992). Widowhood and depression: Explaining long-term gender differences in vulnerability. Journal of Health and Social Behavior, 33(1), 10-24.

Wolf, D. A., Freedman, V., \& Soldo, B. J. (1997). The division of family labor: Care for Elderly Parents. The Journals of Gerontology: Series B, 52B(Special_Issue), 102-109.

Publisher's Note Springer Nature remains neutral with regard to jurisdictional claims in published maps and institutional affiliations.

\section{Affiliations}

\section{Linda Kridahl $^{1} \cdot$ Merril Silverstein $^{2}$}

Merril Silverstein

merrils@syr.edu

1 Demography Unit, Department of Sociology, Stockholm University, Universitetsvägen 10B, SE-106 91 Stockholm, Sweden

2 Maxwell School, Department of Sociology, Falk College, Department of Human Development and Family Science, Aging Studies Institute, 314 Lyman Hall, Syracuse, NY 13244, USA 